\title{
O USO DE DIÁRIOS DE APRENDIZAGEM COMO MEIO DE ENSINO DA LINGUAGEM ESCRITA PARA SURDOS*
}

\author{
Christianne Thatiana Ramos de Souza \\ Cristina Broglia Feitosa de Lacerda
}

\section{Introdução}

A educação bilíngue pressupõe que o surdo precise da língua de sinais (LS) como meio de constituição de si e de seu discurso. Ao se apropriar dessa língua ele terá melhores condições de compreender e apreender a linguagem escrita como uma segunda língua. Segundo Vigotski (1931/1960/2012) ${ }^{1}$, a aquisição da linguagem escrita demanda o domínio de um sistema de signos e significados extremamente complexos, sendo resultado de um processo de desenvolvimento de funções superiores que ocorrem na e pela linguagem oral. Todavia as pessoas surdas, em sua maioria, não têm acesso à linguagem oral como meio de comunicação e de aquisição de significados, este lugar é ocupado pela língua de sinais. Diante desta situação, a língua de sinais será o sistema simbólico mediador no processo de significação vivenciado pelo sujeito surdo, incluindo os significados adquiridos por meio da linguagem escrita.

A escola, principal responsável pelo ensino de conhecimentos científicos e pelo processo de ensino da escrita formal, ainda organiza seu currículo fundamentado numa perspectiva monolíngue, centrada nas características de aprendizagem e comunicação dos ouvintes (FERNANDES, 2006; FERNANDES, 2011). Desta maneira, a escola, em geral, desconsidera a condição bilíngue e a importância da LS para a constituição do sujeito surdo, as “[...] práticas e condições inadequadas em sala de aula acentuam as dificuldades de comunicação, restringindo o acesso do surdo às experiências

"DOI - 10.29388/978-65-86678-60-4-0-f.105-128

${ }^{1}$ Optamos por citar as obras de Vigotski indicando as datas originais de produção seguidas pela data de publicação original em russo e pela data de publicação da tradução que estamos usando (ex: VIGOTSKI, 1924/1926/2013). Quando a data da produção em russo coincidir com a data da publicação do original em russo a citação contará com apenas duas datas (ex: VIGOTSKI, 1929/2000). 
curriculares, uma vez que sua língua de sinais, pré-requisito para seu desenvolvimento, é negligenciada no ambiente escolar" (ALMEIDA, 2016, p. 40).

Uma maneira de lidar com esta situação e reconfigurar o espaço escolar na tentativa de atender às necessidades linguísticas, de aprendizagem e desenvolvimento do público com surdez seria contemplar na organização curricular, no projeto pedagógico e no espaço escolar como um todo, as características linguísticas, sociais e culturais dos estudantes surdos (GÓES; BARBETI, 2014). A proposta educacional bilíngue oferece suporte tanto para a formação de equipes escolares orientadas para atuar de acordo com as necessidades linguísticas destes estudantes quanto para a concretização de experiências práticas de ensino bilíngue. Almeida (2016, p. 40-41) destacou que "qualquer proposta de educação bilíngue para surdos deve privilegiar a organização e a adequação dos espaços escolares permitindo a circulação da língua de sinais e o diálogo entre pares e usuários competentes da mesma língua, em situações reais de interlocução".

Em suma, a escola deve ser um lugar onde a língua de sinais circule de modo efetivo, no qual as trocas comunicativas aconteçam entre estudantes surdos e demais usuários da língua de sinais (surdos adultos, professores bilíngues, intérpretes de LS, estudantes ouvintes usuários da LS, equipe técnico-pedagógica e demais profissionais presentes na escola) favorecendo o exercício e a aquisição de conhecimentos linguísticos e dos significados transmitidos na/pela linguagem. Nestas condições, a língua de sinais poderá assumir centralidade na constituição do sujeito surdo em sua totalidade (ALMEIDA, 2016).

Com base no pressuposto de que a linguagem constitui o sujeito (VIGOTSKI, 1931/1960/2012), a pessoa surda, por ter uma condição bilíngue precisará ter acesso tanto à LS quanto ao português escrito como meios de desenvolvimento. Enquanto a língua de sinais será a base da formação subjetiva permitindo interagir com todos que estão a sua volta e consigo mesmo, a escrita, por ser um sistema mais sofisticado de expressão dialógica, atuará como um propulsor em seu desenvolvimento intelectual, afetivo e social. Para que ambas as línguas possam cumprir seus respectivos papéis no desenvolvimento do sujeito surdo, é necessário que elas tenham funcionalidade tornando-se meio efetivo de expressão e de elaboração do pensamento e do afeto. 
O ensino da escrita ao estudante surdo demanda não somente a atribuição de significado a esta linguagem e a criação da necessidade desta pelo surdo, como também o estabelecimento de uma relação entre a Língua Brasileira de Sinais (Libras) e a modalidade escrita da língua portuguesa, no caso dos surdos brasileiros. O processo de aprendizagem da língua portuguesa escrita pelo surdo implica na aquisição de uma linguagem que não representa a expressão gráfica da Libras, mas se refere à apropriação da forma escrita de uma língua que para ele atuará como segunda língua e que será usada para expressar por escrito os pensamentos formulados em língua de sinais.

Tradicionalmente, a língua portuguesa escrita foi e ainda tem sido ensinada para os surdos, em várias escolas pelo Brasil, de maneira sistematizada e padronizada, esta prática está fundamentada numa concepção de língua como código, como um sistema de decodificação fonético. A compreensão que subjaz esta ideia é de que, ao se apropriar do código, o aluno poderia fazer uso correto da língua. Esta perspectiva propicia ações educacionais que priorizam o ensino de palavras, a utilização destas em frases simples, chegando até as estruturas frasais morfossintaticamente mais complexas. No geral, o ensino da língua portuguesa ocorre por meio de atividades de ditado, cópias, exercícios de repetição e de correção de elementos nas frases, pressupondo ainda o domínio da língua portuguesa oral (PEREIRA, 2009; PEREIRA, 2014b).

O problema encontrado nestas práticas consiste em que os estudantes surdos, em sua maioria, tendem a se apropriar de palavras soltas, com significados dicionarizados e de frases que consequentemente não têm sentido quando tomadas no conjunto do texto. Desta forma, muitas gerações de surdos acreditaram não ser possível aprender a ler e escrever com proficiência, e muitos professores se contentavam com escritas restritas, cheias de imperfeições como o limite possível para seus alunos surdos.

Essa prática levou, e ainda leva, muitos estudantes a desenvolver dificuldades na leitura e compreensão do texto, a representarem a leitura e a escrita como tarefas difíceis e a se sentirem incapazes de ler e escrever. $\mathrm{O}$ resultado foi que os surdos perdiam o interesse pela leitura, e sua escrita, em geral, se constituía de uma justaposição de palavras pouco compreensíveis para o leitor. Ao ler, os estudantes surdos apesar de conseguirem decodificar as palavras não compreendiam o que liam e, ao escrever buscavam em alguma medida representar o que desejavam, mas ora apoiavam-se na língua de sinais, 
e ora na memorização de palavras que não necessariamente representavam em língua portuguesa o que pretendiam dizer (PEREIRA, 2009; PEREIRA, 2014b).

Segundo Fernandes (1999b) a relação entre escrita e oralidade, própria da alfabetização de crianças usuárias do português como língua materna, retira do surdo o prazer de aprender a ler e escrever. Para evitar que isto aconteça é necessário que a leitura e a escrita tenham sentido para o sujeito surdo, por isso é importante que ele tome como base suas experiências e conhecimento de mundo elaborados em língua de sinais além do conhecimento da estrutura e funcionamento da língua portuguesa em si.

Nesse sentido, a língua portuguesa precisa ser abordada como uma língua 'não materna' e as reflexões sobre ela precisam apoiar-se nos conhecimentos linguísticos efetivos da criança surda sobre a língua de sinais. Além disso, Pereira (2009) afirma que "[...] a unidade discursiva na linguagem escrita é o texto e, portanto, a meta do ensino da linguagem escrita deve ser a habilidade de produzir textos, daí a importância de se trabalhar muito o texto em interações na língua de sinais." (p. 64).

Atualmente, no Brasil, poucas são as escolas que conseguem organizar a educação de surdos pautadas no bilinguismo (LACERDA; LODI, 2010; LODI, 2013). Existem experiências bem-sucedidas, mas pontuais e que não atingem a maioria dos estudantes surdos. A escola, na maioria dos casos, mantém um currículo, prioritariamente, estruturado de acordo com as necessidades educacionais e comunicativas dos ouvintes. A língua portuguesa, então, não é ensinada como segunda língua aos surdos, visto que as ações pedagógicas e metodológicas não conseguem atender às características de aprendizagem e de comunicação deste público (FERNANDES, 2006; SANTOS, 2013)

De acordo com Lodi (2013), independente do modelo bilíngue empreendido, o ensino da língua portuguesa escrita como segunda língua continua sendo um problema comum e persistente. Dentre os aspectos que constituem os problemas encontrados no ensino da escrita destacamos alguns: domínio da Libras pelo aluno surdo, ausência da participação da Libras como língua de elaboração e de organização dos significados adquiridos por meio da escrita, instrumentalização da língua portuguesa escrita, não imersão do aluno em uma prática social que faça uso da linguagem escrita, ausência ou baixa frequência de práticas de leitura, entre outros (FERNANDES, 1999a; 
GUARINELLO, 2007; LACERDA; LODI, 2010; LODI, 2013; FORMAGIO; LACERDA, 2016).

Neste cenário, há a necessidade de modificações curriculares na escola para que de fato ela consiga atender aos princípios de equidade e atenção a diversidade, que no caso do público surdo esta demanda situa-se na área linguística e comunicativa (FERNANDES; MOREIRA, 2009; FERNANDES; MOREIRA, 2014).

Assim, segundo Pereira (2014b), a fundamentação de práticas de ensino de leitura e escrita em uma concepção de linguagem como atividade discursiva modifica o objetivo do ensino da modalidade escrita da segunda língua para o surdo. De acordo com esta concepção a leitura implica em compreensão, sendo esta "uma atividade interativa de produção de sentidos, que se realiza com base nos elementos linguísticos presentes no texto e na sua forma de organização" (p. 149). A escrita, por sua vez, passou a ser concebida como a habilidade de produção textual, os estudantes surdos devem fazer uso da língua e neste processo elaborar hipóteses sobre seu funcionamento, sozinhos ou em interação com o professor. A estrutura gramatical passa a ser ensinada durante o uso da língua pelos estudantes, isto é, por meio da escrita de textos os surdos têm acesso à gramática da segunda língua (FERNANDES, 1999b; PEREIRA, 2014b).

De acordo com Peixoto (2006), as pistas visuais presentes na organização da escrita também são utilizadas pelo surdo no processo de aquisição e produção desta. Neste sentido, o surdo elabora hipóteses acerca da escrita com base tanto na língua de sinais quanto nos elementos visuais característicos da escrita alfabética. A referência para o ensino da escrita do português, considerando este aspecto, não deve ser oral, mas visual.

O ensino da escrita para o público surdo deve prescindir de atividades que abordem a análise linguística como referência para o processo de ensino desta parcela de alunos. "O ponto de partida das atividades de leitura e de escrita para Surdos deve ser sempre o texto, e a compreensão das unidades de sentido que o compõem será mediada pela língua de sinais" (FERNANDES, 2011, p. 114).

A imersão do aluno em uma rede de interações linguísticas com usuários competentes da língua de sinais potencializa o ensino da escrita tanto em seu aspecto formal (gramática, ortografia, etc.) quanto em relação ao desenvolvimento de habilidades de leitura e produção textual (GIORDANI, 
2015). Neste sentido, Pereira (2014a) destacou que, por meio da interação ocorrida em sala de aula no ensino da escrita, o professor deve mostrar ao aluno surdo que esta linguagem tem significados e pretende comunicar algo. A tradução para a língua de sinais, de diferentes textos e mensagens escritas auxiliam o aluno a compreender a função que a escrita cumpre como meio de comunicação e de aquisição de conhecimentos.

Sobre as práticas de ensino e as interações que ocorrem entre professor e aluno surdo no processo de aquisição da linguagem escrita, Guarinello (2007) ressaltou que a mediação do adulto é condição necessária para que esta aquisição ocorra, já que é papel do adulto mediar, orientar e atribuir sentido à escrita produzida pelo aluno. Esse processo envolverá a construção conjunta de conhecimentos que mediarão a atribuição de sentidos aos textos lidos.

Neste sentido, defendemos a educação de surdos fundamentada nos pressupostos do bilinguismo e a criação de espaços escolares bilíngues onde a Libras seja de fato tomada como a língua de constituição, comunicação e ensino dos surdos, e a língua portuguesa escrita tratada efetivamente como segunda língua, a qual contribuirá para o avanço do desenvolvimento a níveis cada vez mais abstratos e complexos, conforme pressupõe Vigotski (1931/1960/2012; 1934/2014).

A criação de um espaço educacional bilíngue para surdos demanda práticas de ensino adequadas as necessidades linguísticas e comunicativas destes púbico, tendo a Libras como língua de instrução. Neste contexto o ensino da linguagem escrita também requer ações educativas que tornem a escrita uma linguagem necessária tanto para a comunicação do surdo com a comunidade em geral quanto para a sua constituição como sujeito. Desta maneira, consideramos relevante analisar o uso do diário de aprendizagem como um recurso mediador do processo de ensino e aprendizagem da linguagem escrita por estudantes surdos.

Assim, o objetivo geral deste estudo foi investigar o uso do diário de aprendizagem como um espaço de interação e de diálogo entre professora e estudantes surdos no processo de aquisição da língua portuguesa como L2. Especificamente buscamos caracterizar as interações ocorridas entre professora e alunos ao longo da produção dos diários; e analisar as estratégias usadas pela professora nos diálogos com os estudantes no ensino da língua portuguesa como L2. 


\section{Aspectos Teórico-Metodológicos}

A pesquisa foi realizada em uma escola municipal de Ensino Fundamental situada no interior de São Paulo na qual se desenvolve um Programa de Inclusão Bilíngue de estudantes surdos. Esta escola funciona como um polo de inclusão agregando estudantes surdos residentes no município onde está situada e outros que moram em municípios vizinhos. Para participar do programa os estudantes precisam manifestar interesse ou receber autorização dos pais e/ou responsáveis para tal. O Programa de Inclusão Bilíngue ocorre a vários anos, por meio de uma parceria entre pesquisadores de uma universidade pública e a Secretaria Municipal de Educação (para maior detalhamento conferir LACERDA, 2014; LACERDA, 2016).

Participaram deste estudo a professora de Língua Portuguesa como segunda língua, que chamaremos de Solange, e seis alunos surdos do Ensino Fundamental II com idades entre 14 e 18 anos. Todos os participantes eram usuários da Libras.

Para contemplar o objetivo proposto analisamos os diários produzidos pelos estudantes como parte das atividades desenvolvidas nas aulas de Língua Portuguesa como L2. Entretanto, neste artigo optamos por utilizar como ilustração das análises os textos retirados dos diários de apenas três estudantes: Kauã, Gisele e lana. Os nomes atribuídos aos participantes são fictícios a fim de preservar suas identidades.

No que se refere a produção dos diários, a professora participante deste estudo afirmou que esta proposta foi elaborada e executada como uma atividade pedagógica cujo objetivo era

[...] atribuir uma funcionalidade à língua portuguesa, ao mesmo tempo em que valorizássemos o caráter comunicativo da língua, ou seja, os alunos escreveriam textos com uma função comunicativa (eu lia e conversava com eles por escrito sobre o que escreveram), sem o intuito de atribuição de nota. Era uma atividade em que os alunos conseguiam mais livremente expressar ideias e sentimentos e aproveitávamos para fazer uma reflexão sobre os modos de expressão na modalidade escrita da língua (Solange). 
Os diários eram produzidos cotidianamente a pedido da professora que solicitava aos estudantes que registrassem em seus diários ocorrências de seu dia-a-dia. Uma vez por semana, os diários eram recolhidos e Solange fazia a leitura e suas considerações sobre os textos. O diário não era considerado como uma atividade avaliativa no sentido de atribuição de nota, mas era fortemente incentivado pela professora e utilizado como um meio de acompanhar o processo de aquisição e produção da linguagem escrita pelos estudantes. A escrita dos diários se deu ao longo do período de um ano e meio.

Segundo Carletto (2012), o diário pode ser considerado

[...] como um dos gêneros da literatura autobiográfica nos quais o autor registra vivências e sentimentos ante o mundo que o cerca. É daí que provém seu caráter intimista e confidente. $\mathrm{O}$ diário apresenta-se como um testemunho do cotidiano, seus registros não são necessariamente diários e geralmente são feitos por meio de narrações, de palavras soltas, de poemas, de colagens e de pequenos desenhos, podendo ainda apresentar descontinuidades (p. 10).

Em geral, o conteúdo do diário é privado, acessível somente ao próprio autor ou àqueles que têm a permissão deste para lê-lo. Isto favorece o caráter intimista e confidente deste gênero. Que segundo Carletto (2012), tem relação "[...] com os acontecimentos relacionados com o seu autor, que imprime um estilo próprio e particular, externando um conteúdo geralmente inacessível aos demais, o que caracteriza o diarismo como uma atividade da esfera privada" (p. 8).

Bastos (2016) afirmou que o gênero diário possui algumas características típicas. A primeira delas é a estrutura composicional marcada pela datação, vocativo e despedida. O conteúdo temático é o segundo aspecto tipicamente constitutivo do diário. No geral, o principal tema abordado no diário diz respeito ao relato de situações da vida pessoal do autor.

De acordo com Reis (2012), quando usado com uma finalidade didático-pedagógica o gênero diário passa a ser denominado 'diário de aprendizagem' que pode ser considerado como uma variação do diário íntimo. A diferença entre ambos se situa na definição, enquanto o diário de aprendizagem favorece o diálogo entre professor e estudantes com uma finalidade avaliativa e se configura como um lugar de construção de 
conhecimento, o diário íntimo se constitui em um espaço de diálogo do autor consigo mesmo, de reflexão sobre si e sobre seu cotidiano. Nesse sentido, o diário de aprendizagem é um lugar de reflexão, estando voltado para o que ocorre no ambiente escolar, sobre o que acontece em sala de aula, sobre a relação de ensino-aprendizagem.

Voltando nosso olhar para os diários utilizados neste estudo é importante destacar que o material coletado, embora se refira a uma escrita sobre o cotidiano dos estudantes, não tinha como finalidade inicial ser um espaço unicamente privado e de acesso exclusivo do estudante. Deste modo, o diário produzido pelos estudantes participantes desta pesquisa apresentava características tanto do diário íntimo quanto do diário de aprendizagem. Reis (2012) afirmou que o encontro entre as variações do texto caracteriza o movimento pelo qual o gênero vai passando e por meio do qual vai sendo

[...] não apenas atualizado e mantido, mas também modificado. Surgem daí outros gêneros que constituirão sua própria história, ainda que tomem emprestado algumas velhas características, como acontece com os blogs, novas formas de diário em nossos dias, mas dinamicamente atualizados ao incorporar tantos outros elementos da internet e de sua linguagem virtual (p. 129, grifo da autora).

Para esta autora, embora a nomeação dos tipos de diário seja utilizada como forma de marcar as diferenças internas entre os textos, do ponto de vista do gênero independente da denominação ambos são constituídos por marcas definidoras do diário.

A partir da caracterização feita por Reis (2012), os diários analisados nesta pesquisa foram definidos como sendo de aprendizagem, pois foram propostos como uma estratégia e um recurso de ensino-aprendizagem da língua portuguesa escrita como L2. Por ser produzida a partir de uma solicitação escolar, a redação do diário constituiu-se como uma comunicação entre Solange e os estudantes. A professora atuava como proponente da atividade e como mediadora no processo de produção e aprendizagem da escrita, por meio de intervenções contínuas e individualizadas ao longo dos textos motivava os alunos na produção dos diários. Deste modo, a professora atuava na zona de desenvolvimento proximal de cada estudante mediando o processo de apropriação dos conhecimentos sobre a escrita do português (VIGOTSKI, 2017). 
A análise dos registros feitos nos diários considerou as estratégias de intervenção usadas por Solange no sentido de mediar o processo de apropriação e elaboração pelos estudantes da escrita formal da língua portuguesa, bem como as estratégias usadas para a modificação do conteúdo dos registros, visando a ampliação do texto e um aprofundamento na abordagem dos assuntos apresentados.

\section{Análise e Discussão}

A partir da leitura do conteúdo dos diários as ações da professora foram caracterizadas como estando voltadas para a forma e para o conteúdo da escrita. Quanto à forma, as intervenções tinham como foco o ensino dos aspectos normativos gramaticais da língua portuguesa. Em relação ao conteúdo, as intervenções estavam voltadas para a elaboração textual considerando ampliação do texto, explicitação das informações apresentadas e escolhas lexicais.

De maneira introdutória apresentamos na Figura 1 um excerto do primeiro texto do diário de um estudante como exemplo da produção inicial encontrada nos diários dos demais estudantes.

Figura 1 - Texto retirado do diário de Kauã produzido em 03/05/2015

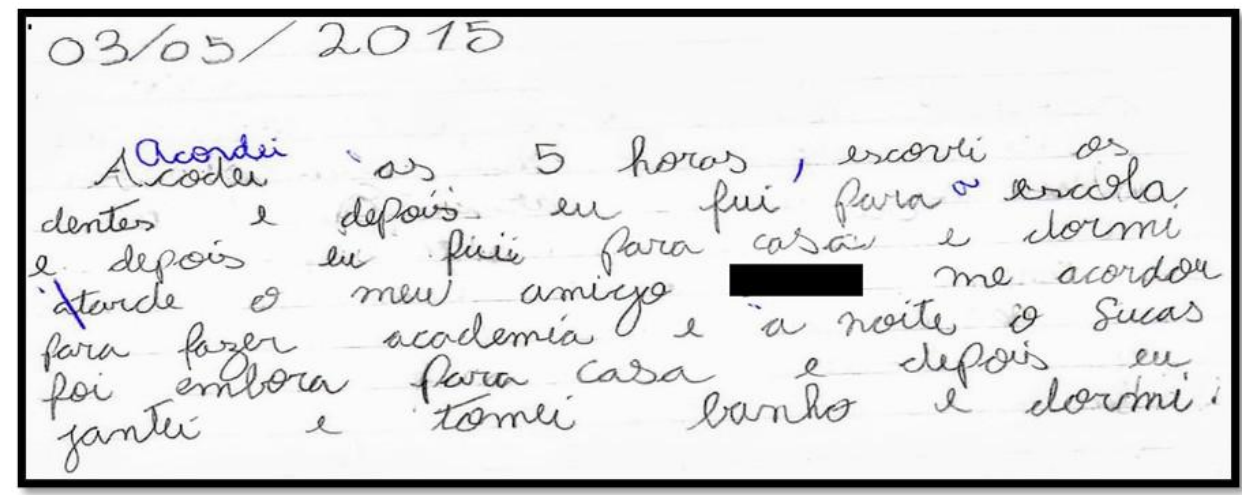

Fonte: Diário do estudante

Conforme pode ser observado na Figura 1, o tema abordado pelo estudante em seu diário diz respeito a sua rotina. $\mathrm{O}$ conteúdo revela o relato do que ocorreu ao longo de um dia em sua vida cotidiana. Inicialmente, os 
textos produzidos por todos os estudantes eram constituídos por informações sobre o horário em que acordavam, pela enumeração e nomeação das atividades realizadas ao longo do dia, finalizando com a hora em que dormiam.

Como os estudantes tinham pouca ou nenhuma experiência com o gênero diário, Solange propôs inicialmente como tema a descrição de suas atividades cotidianas. Deste modo, o relato das experiências vividas no dia a dia de cada um se tornou o principal tema dos diários.

É importante destacar que a professora utilizou a produção do diário como uma atividade de escrita que se distinguisse daquelas feitas em sala de aula. Assim, a escrita dos diários se tornou um meio de ensino-aprendizagem significativo da língua portuguesa como L2, que incentivava a autoria por meio de uma escrita mais independente e autônoma.

Em relação a análise acerca do processo de ensino-aprendizagem de aspectos formais da língua portuguesa apresentamos dois excertos ilustrativos (Figura 2 e Figura 3) de como ocorreram as interações dialógicas entre professora e estudantes surdos no diário. Os textos utilizados demonstram um diálogo ocorrido entre Solange e uma estudante sobre a grafia de uma palavra.

Figura 2 - Texto retirado do diário de lana produzido em 29/05/2015

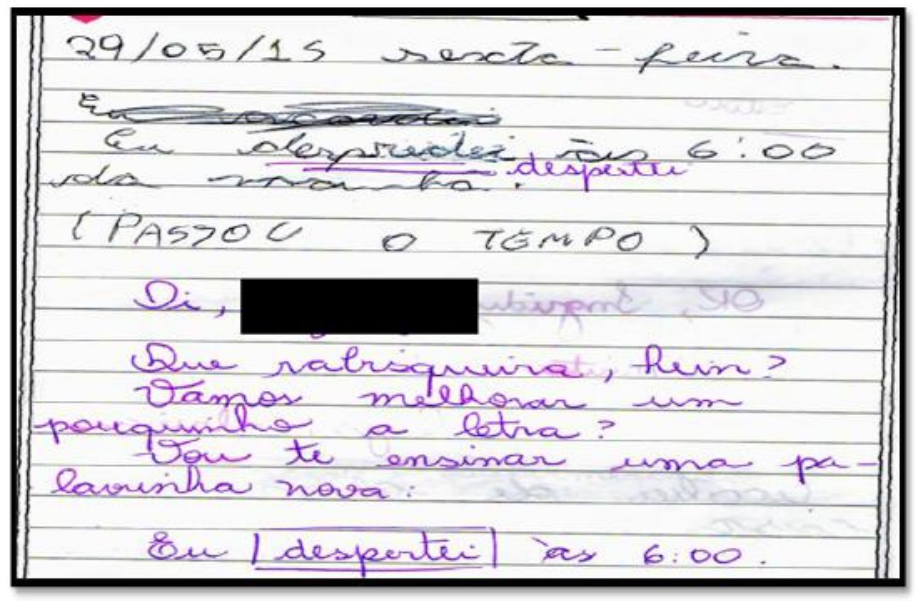

Fonte: Diário da estudante 
Figura 3 - Texto retirado do diário de lana produzido em 18/06/2015

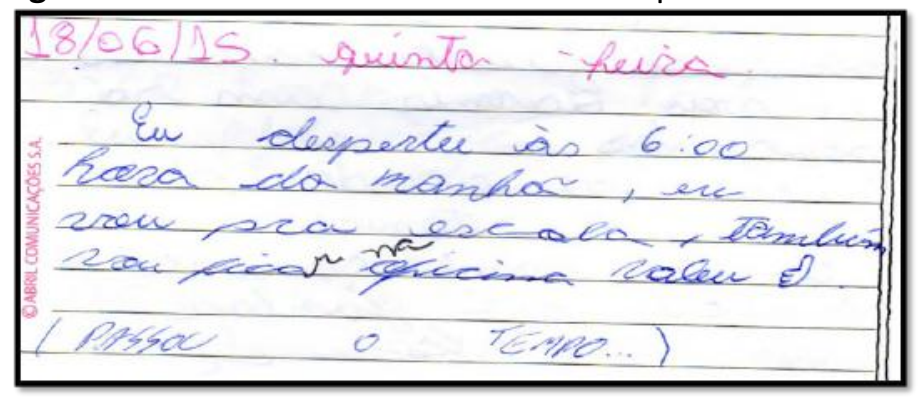

Fonte: Diário da estudante

O trecho do diário apresentado na Figura 2 mostra uma intervenção feita pela professora voltada para o ensino da grafia de palavras em língua portuguesa. Nesta imagem é possível observar que Solange grifa a palavra escrita pela estudante e apresenta a grafia formal da palavra ao abaixo da que foi sublinhada e ao final do texto, quando reescreve a frase produzida pela estudante. De um modo geral, a professora realizava intervenções individuais nas produções dos estudantes. A leitura dos diários era seguida de marcas ou comentários que visavam chamar a atenção deles para os aspectos normativos da escrita em língua portuguesa.

As intervenções eram feitas por meio de diferentes marcadores ou utilizando distintas estratégias de diálogo, como: a complementação de palavras ou substituição de letras nas palavras escritas; o uso de traços, círculos ou $X$ feitos sobre as letras ou palavras grafadas de maneira diferente do padrão da língua portuguesa escrita (Figura 2); ou ainda, o uso de comentários ao final do texto chamando a atenção do estudante para algo que havia sido indicado no texto ou solicitando a reescrita das palavras.

As inadequações que aparecem nos textos dos estudantes em relação às normas da língua portuguesa escrita são de natureza diversa (gramaticais, ortográficas, lexicais). Contudo, chamamos a atenção para um aspecto importante em relação às ações de Solange, que parece eleger apenas um ou alguns aspectos, a cada intervenção, para serem apontados ao estudante, focando sua ação em poucos itens por vez.

É possível observar nas ações da professora uma consciência em relação aos seus objetivos, que são motivar o estudante a escrever e ensinar os aspectos formais da língua portuguesa escrita. Ao mesmo tempo em que 
valoriza o que foi aprendido, demonstrando aos estudantes seus avanços, atua como mediadora no processo de aquisição da língua (VIGOTSKI, 1931/1960/2012; 1934/2014).

Em relação à Figura 3, a estudante grafou a palavra despertei conforme o modelo indicado anteriormente (Figura 2) pela professora. Aos poucos a estudante foi deixando menos marcas de refacção em seu texto, apresentando uma produção mais "limpa", do ponto de vista da ausência destas marcas, e mais organizada, no aspecto da clareza na grafia das palavras, atendendo a solicitação feita por Solange (Figura 2) sobre a rabisqueira e melhora da letra.

Mayrink-Sabinson (1997) discutiu que o processo de ensino da língua portuguesa escrita envolve, também, correções ortográficas em relação à qualidade da letra usada pelo estudante. Estas correções podem ser feitas tanto por meio de comentários deixados no texto, conforme pode ser visto na Figura 2 quando a professora pede a melhora da letra da estudante, quanto por meio de marcas deixadas em palavras escritas no texto, como as que foram feitas pela professora ao longo dos diários de todos os estudantes.

A autora supracitada afirmou também que estas marcas escritas, que se caracterizam como interferências diretas no texto dirigidas ao estudante, mobilizam mudanças na produção escrita deste e se configuram como um espaço de interlocução entre o autor (estudante) e o interlocutor (adulto letrado). Por meio desta cooperação, Solange atua na zona de desenvolvimento proximal dos estudantes e vai mediando o processo de internalização dos aspectos formais da escrita (VIGOTSKI, 1934/2014), enquanto o estudante, em uma atitude responsiva (BAKHTIN, 2011), incorpora as sugestões, modificando seu texto e aproximando-se da escrita padrão da língua portuguesa.

Mayrink-Sabinson (1997) apontou ainda, a partir dos resultados obtidos em seu estudo sobre o papel do interlocutor no processo de aquisição da escrita por crianças ouvintes, que à medida que avançavam a idade e a série dos estudantes, a professora passava a concentrar suas intervenções cada vez mais nos aspectos ortográficos e de organização do texto. Isto nos leva a pensar sobre a necessidade de priorizar, inicialmente, a compreensão do estudante sobre o significado da escrita, sobre o porquê e para que escrever, sem deixar de lado ou atribuir um valor secundário às regras e normas gramaticais (PEREIRA, 2009). O conhecimento sobre o vocabulário e as normas gramaticais é fundamental para que os estudantes sejam capazes de construir 
e compreender os textos (VIANA; LIMA, 2016), mas estes podem e devem ser aprendidos por meio da prática da escrita. Deste modo, a escrita ganha significado e torna-se um meio de constituição do sujeito (VIGOTSKI, 1931/1960/2012; PINO, 2005).

Vamos agora ao segundo aspecto de nossa análise que diz respeito ao conteúdo dos textos produzidos. Sobre essa dimensão destacamos as questões referentes ao processo de elaboração do texto no que diz respeito ao tema abordado, uso do léxico, ampliação e explicitação de ideias. A seguir apresentamos um exemplo extraído do diário de um estudante e faremos as considerações acerca das intervenções e das estratégias usadas pela professora por meio das interlocuções com o estudante.

Figura 4 - Texto retirado do diário de Kauã produzido em 01/03/2016 e $02 / 03 / 2016$

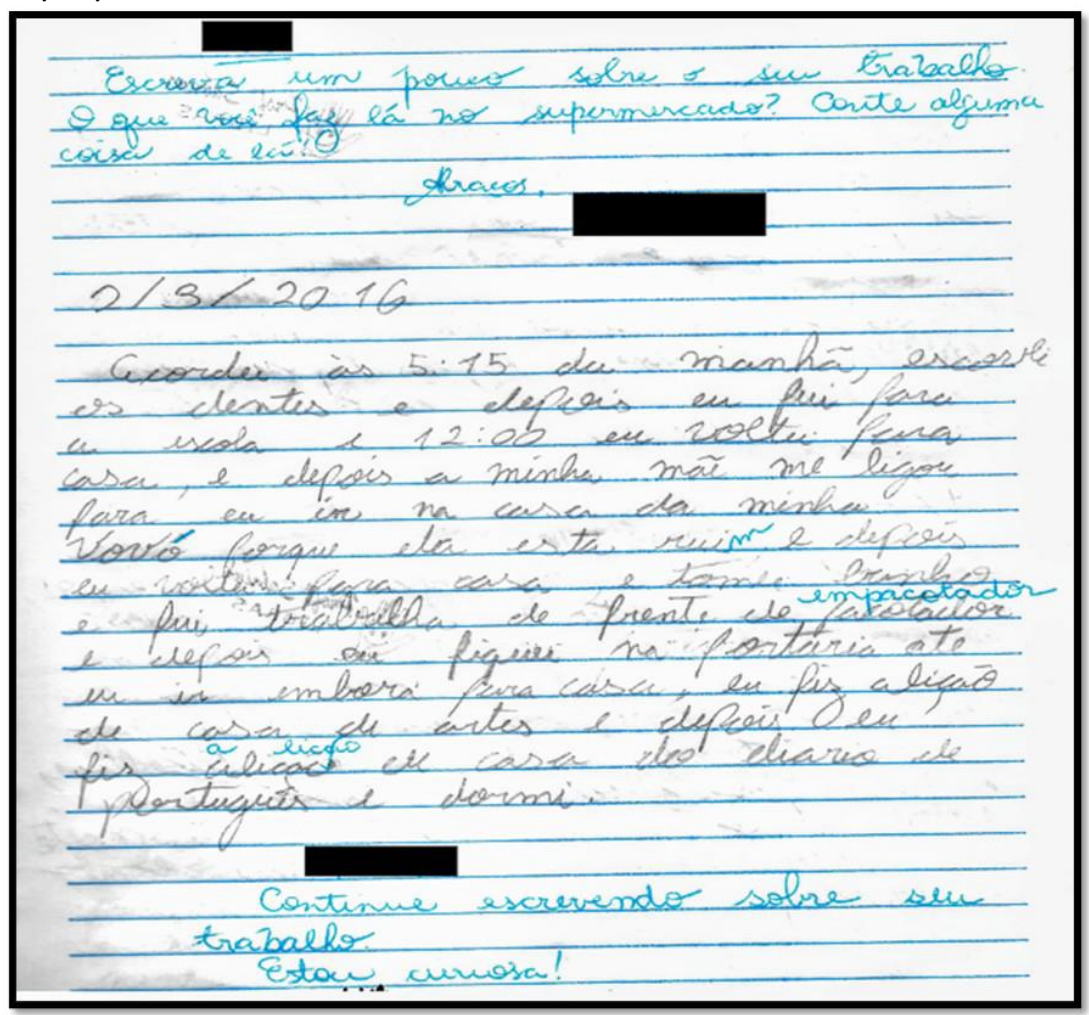

Fonte: Diário do estudante 
A Figura 4 mostra uma sequência dialógica em que Solange pediu ao estudante que falasse um pouco mais sobre seu trabalho e especificou, por meio de questionamentos, o que gostaria de saber. A solicitação da professora estimulou o estudante a ampliar seu texto e a inserir mais informações sobre as atividades que realizava no trabalho, narrando de forma mais detalhada sobre este tema.

Em textos que antecederam este, e em outros que se seguiram, Solange costumava solicitar que o estudante falasse de forma mais detalhada sobre o tema abordado ou que abordasse outros temas, além da descrição das atividades que realizava ao longo de seu dia. Na situação ilustrada pela Figura 4, Solange sugeriu um tema específico para o relato feito pelo estudante. Isto ocorreu por meio da solicitação para que o estudante escrevesse sobre seu trabalho, conforme pode ser visto na pergunta que antecede o texto escrito pelo estudante. Antes de fazer essa sugestão direta sobre um tema específico para o relato, Solange fez vários pedidos de variação do tema sem indicação de um assunto específico. O relato produzido após a solicitação da professora trata sobre a experiência laboral do estudante e atende ao pedido feito. Após essa modificação temática, Solange seguiu pedindo mais detalhes sobre o novo tema abordado e demonstrou interesse sobre o conteúdo relatado pelo estudante como uma maneira de motivá-lo a ampliar seu texto, conforme pode ser visto na solicitação final após o texto.

Durante alguns dias, este estudante somente comentava que havia começado a trabalhar em um supermercado e informava o horário de início e final da jornada que cumpria diariamente. De forma atenta às intervenções da professora, o estudante seguiu ampliando seus textos quando solicitado, fato identificado tanto na Figura 4 quanto em outros trechos do diário. Deste modo, a narrativa feita pelo estudante ficou cada vez mais detalhada e novas palavras foram incorporadas ao vocabulário usado nos textos, resultando em uma modificação qualitativa na sua produção escrita.

Ressaltamos que este estudante costumava escrever de forma muito sintética, descrevendo somente as principais atividades realizadas durante 0 dia, e pouco detalhava os acontecimentos em cada atividade realizada. Em virtude disso, Solange pedia constantemente uma descrição pormenorizada, por meio de questionamentos sobre os acontecimentos narrados, estimulando o estudante a ampliar e detalhar mais seu texto. 
Os temas abordados por este estudante, como o primeiro emprego, administração do próprio dinheiro e relacionamento afetivo, demonstram experiências de um jovem prestes a entrar na idade adulta. Pereira (2009; 2014b) discutiu que o conhecimento de mundo do sujeito surdo adquirido por meio da língua de sinais associado ao conhecimento sobre a língua portuguesa escrita colabora para que o sujeito tenha conteúdo para se expressar e consiga fazê-lo de forma convencional.

Este estudante adquiriu a língua de sinais e linguagem escrita tardiamente, seu texto apresenta marcas de um modo sintético de narrar suas atividades, mesmo quando modifica os temas ou amplia seu relato. Todavia, as mudanças impressas em seus textos também indicam um avanço no domínio da escrita e um desempenho cada vez mais autônomo no uso da língua portuguesa convencional.

À medida que os estudantes avançavam na escrita, a professora passou a pedir a introdução, variação ou modificação de temas. Pedia ampliação das narrativas, o que geralmente ocorria quando os estudantes escreviam de forma resumida, limitando-se a uma descrição sequencial de eventos. A sugestão de ampliação do texto também colaborava para a ampliação do vocabulário escrito, para a apropriação de escolhas lexicais na linguagem escrita e para a ampliação de conhecimento de mundo.

Interessante destacar que tanto o detalhamento na narrativa feito por meio da explicitação de opiniões, as justificativas para as escolhas feitas, a demonstração de que estavam levando em consideração as sugestões de Solange sobre o que fazer e como organizar suas atividades diárias, quanto à coerência textual, resultaram do diálogo constante entre professora e estudantes. Por meio de seus comentários, a professora foi marcando os aspectos que, em sua opinião, precisavam ser melhor desenvolvidos, ao mesmo tempo em que oferecia elementos (fazia perguntas sobre o conteúdo abordado, indicava o que deveria ou não ser abordado no texto, apresentava palavras novas, sinônimos, etc.) que auxiliavam os estudantes a incorporar essas modificações no texto.

Para concluir nossa análise apresentamos a Figura 5 que ilustra o modo como se apresentavam os textos produzidos pelos estudantes ao final do processo de escrita dos diários. 
Figura 5 - Texto retirado do diário de Gisele produzido em 21/04/2016

\section{6}

Ev depertei, eu a minha mä, meu pai, $\theta$ mercado

Pran pergin

- Porpque nos.

e a pomos no to

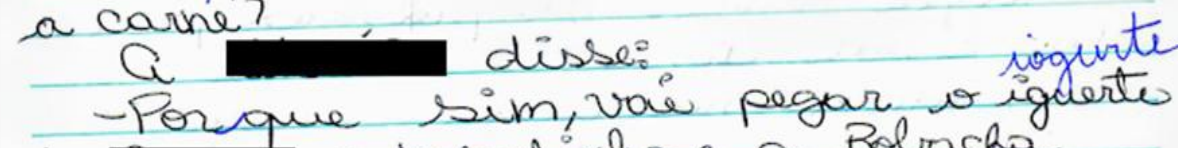

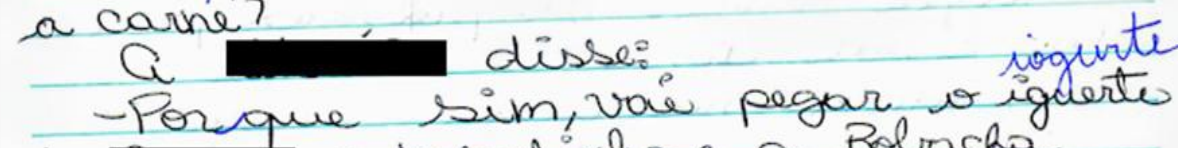

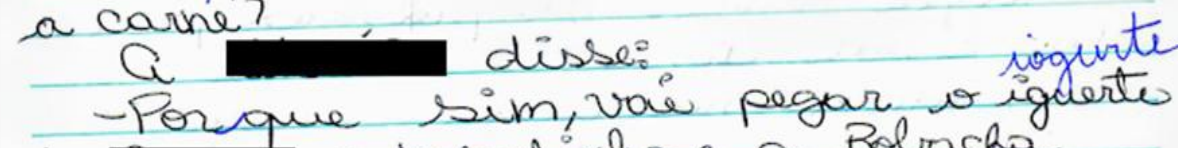
estamos comprando do so salgadinho e a Bobacha Peguei 3 coisas e cologuei no corrinho parguntei pro mere pai! e também nós precisamos comprar arroz e peijao?
Weu pai disse:

- Boquer sábado a agra a gente vamos pazer churrasco.

Cheguei em casa descansi e dormi. Naqui $18: 00$ hovas en brinquei com

a minha amiga chamada Cis 19:25 hora liquei of TV assisti "Sotalmente Nemais" a Norni.

Fonte: Diário da estudante

Na Figura 5 é possível observar que o texto elaborado pela estudante continha vários recursos gramaticais e composicionais típicos de um texto narrativo, o que representa uma mudança qualitativa em relação aos textos iniciais, predominantemente descritivos de uma sequência de atividades realizadas durante um dia. Outra característica que destacamos se refere ao conteúdo temático, aqui a estudante narrou sobre um evento ocorrido em família narrando diálogos ocorridos entre os integrantes durante a ida ao mercado. A estudante não focou na descrição de sua rotina, mas se voltou 
para a narrativa de uma interação entre ela e sua família em uma atividade específica do seu dia.

Embora nem todos os estudantes tenham chegado a produzir narrativas detalhadas, abordando temas diversificados e com uma coerência textual totalmente adequada à normatização da língua portuguesa, todos tiveram avanços em suas produções, pois partiram de um momento em que a escrita do diário resumia-se a descrever a hora que acordavam, o que haviam comido nas refeições, as aulas tidas na escola e concluíam informando que haviam dormido. O principal e, por vezes, único tema abordado, era a rotina básica (como mostra a Figura 1).

Aos poucos, a narrativa sobre a rotina foi ganhando mais elementos, passaram a contar sobre as atividades que faziam em família durante a semana, posteriormente, aos finais de semana, e alguns passaram a narrar sobre vivências em outros locais de circulação e com outras pessoas. Ao final do período de produção do diário, todos tiveram avanços tanto na organização textual, quanto na modificação e diversificação do conteúdo, conforme pode ser observado na Figura 5. A presença de um leitor qualificado que incentiva e confere sentido à escrita, favorece o fortalecimento do escritor, que por sua vez, se sente motivado a escrever mais e melhor.

Quando falamos em formação do escritor, não nos referimos à preparação do estudante para tornar-se um escritor profissional, mas um escritor/autor que tenha conhecimento de diferentes gêneros discursivos e que consiga se expressar por meio deles de forma compreensível e autônoma (SILVA; STURM, 2013). Ao adquirir confiança em sua capacidade de produção textual, o estudante pode passar a usar a escrita para refletir, organizar-se, elaborar emoções, entre outras funções (VIGOTSKI, 1931/1960/2013; 1934/2014).

Em geral, os surdos têm dificuldade com a escrita e não chegam, em sua maioria, à autoria e a produção de uma escrita autônoma, muitas vezes, devido ao processo de ensino da língua portuguesa ao qual estão submetidos (FERNANDES, 1999a; 2006; PEREIRA, 2009; 2014a; 2014b; GIORDANI, 2015). Os estudantes participantes desta pesquisa caminharam em direção à escrita autônoma e autoral, permitindo elaborações acerca de suas vivências. 


\section{Considerações Finais}

Com o intuito de investigar o uso do diário de aprendizagem como um espaço de interação e de diálogo entre professora e estudantes surdos no processo de aquisição da língua portuguesa como L2, fizemos uma leitura dos diários buscando analisar as intervenções realizadas pela professora, bem suas interlocuções com os estudantes sobre as características normativas da língua portuguesa e sobre o conteúdo textual.

As evidências analíticas indicaram que por meio do diário, a professora mediou processo de aquisição da linguagem escrita pelos estudantes surdos através de duas estratégias principais de intervenção: o apontamento das inadequações nas produções em relação a ortografia, gramática, pontuação, acentuação, etc. e a indicação do padrão normativo da língua portuguesa; os comentários sobre o conteúdo ou estrutura textual que dialogavam com o fluxo e com as características da produção individual, adequando-se tanto ao nível de desenvolvimento de cada estudante quanto ao seu potencial de ação e de aprendizagem.

Destacamos a postura dialógica assumida pela professora na leitura dos diários. Ainda que seu foco tenha sido destacar as inadequações na escrita dos estudantes, a professora assume uma posição de quem dialoga, pergunta e sugere. Coloca o estudante em posição ativa e tensiona, propõe e pergunta. A professora, nos casos aqui analisados, atuou como mediadora e figura de referência na relação dos sujeitos surdos com a linguagem escrita, assumindo o papel de adulto letrado, sendo modelo para os sujeitos em constituição, conforme ressaltou Mayrink-Sabinson (1997). De acordo com esta autora, o processo de aquisição da linguagem acontece na interlocução entre os sujeitos, e esta inter-relação implica um constante movimento de incorporação e tomada da palavra do outro, sendo este outro um interlocutor fisicamente presente ou representado, mas "necessário ponto de referência para este sujeito em constituição" (p. 41).

A escrita dos diários proporcionou aos estudantes uma experiência de escrita autônoma e o desenvolvimento de uma competência da escrita formal da língua portuguesa. Além disso, o diário se configurou como um espaço de ensino da linguagem escrita de forma significativa por ser um lugar onde os estudantes tinham a oportunidade de narrar suas experiências de vida e ao 
mesmo tempo fazer uso da língua portuguesa como um meio de comunicação, bem como se apropriar dos aspectos normativos da língua.

O movimento de aprendizagem das normas da escrita da língua portuguesa observado em todos os diários não segue uma linearidade e nem um padrão crescente de internalização. Pelo contrário, é marcado por evoluções e retrocessos, que não necessariamente significam um retorno ao ponto inicial, mas que demonstram que a conversão dos conhecimentos que estão em negociação demanda experiência no uso do objeto de conhecimento que está sendo ensinado e diálogo sobre as formas de uso deste, para que, finalmente, possa ser usado de forma autônoma. Esse movimento envolve conflito e a resolução destes, portanto, é importante destacar que as ações da professora seguem um ritmo que respeita e acompanha o processo de cada estudante individualmente.

Esta forma de intervir se mostra respeitosa e em diálogo com os estudantes, que seguem escrevendo e vão, aos poucos, incorporando as informações trazidas pelas professoras. Ao longo do tempo é possível ver que os estudantes vão modificando sua produção escrita e vão se apropriando de várias regras de uso da língua portuguesa. Esse trabalho fundamental da professora parece abrir espaço para uma escrita mais autônoma e de autoria, podendo criar condições para tornar a escrita um meio de reflexão sobre si e sobre o outro.

\section{Referências}

ALMEIDA, D. L. Português como segunda língua para surdos: a escrita construída em situações de interação mediadas pela Libras. 2016. 244 f. Tese (Doutorado em Educação Especial) - Centro de Educação e Ciências Humanas, Universidade Federal de São Carlos, São Carlos, São Paulo, 2016.

BAKHTIN, M. M. Estética da criação verbal. 6. ed. São Paulo: Editora WMF Martins Fontes, 2011.

BASTOS, A. S. O. P. O diário na sala de aula: articulando análise linguística, leitura e produção textual. Linguagens e Letramentos, v.1, n. 2, 2016. Disponível em: 
http://revistas.ufcg.edu.br/cfp/index.php/linguagensletramentos/article/ view/40 Acesso em: 16 ago. 2017.

CARLETTO, R. Diário: a caracterização de um gênero singular. X ENCONTRO DO CELSUL - CÍRCULO DE ESTUDOS LINGUÍSTICOS DO SUL UNIOESTE., 2012, Cascavel, Anais..., Cascavel, Paraná, Universidade Estadual do Oeste do Paraná, 24 a 26 de outubro de 2012.

FERNANDES, S. É possível ser surdo em português? Língua de sinais e escrita: em busca de uma aproximação. In: SKLIAR, C. (Org.) Atualidade da educação bilíngue para surdos. Porto Alegre: Mediação, 1999a, p. 59-82.

FERNANDES, S. O som: esse ilustre desconhecido. In: SKLIAR, C. (Org.) Atualidade da educação bilíngue para surdos. Porto Alegre: Mediação, 1999b, p. 95-102.

FERNANDES, S. Práticas de letramento na educação bilíngue para surdos. Curitiba: SEED, 2006.

FERNANDES, S. Educação de surdos. Curitiba: Ibpex, 2. ed., 2011.

FERNANDES, S.; MOREIRA, L. C. Desdobramentos político-pedagógicos do bilinguismo para surdos: reflexões e encaminhamentos. Revista Educação Especial, Santa Maria, v. 22, p. 225-236, 2009.

FERNANDES, S.; MOREIRA, L. C. Políticas de educação bilíngue para surdos: o contexto brasileiro. Educar em Revista, Curitiba, Edição Especial, n. 2, p. 51-69, Editora UFPR, 2014.

FORMAGIO, C. L. S.; LACERDA, C. B. F. Práticas pedagógicas do ensino de português como segunda língua para alunos surdos no ensino fundamental. In: LACERDA, C. B. F.; SANTOS, L. F.; MARTINS, V. R. O (Orgs.) Escola e Diferença: caminhos da educação bilíngue para surdos. São Carlos: Edufscar, 2016, p. 169241. 
GIORDANI, L. F. Encontros e desencontros da língua escrita na educação de surdos. In: LODI, A. C. B.; HARRISON, K. M. P.; CAMPOS, S. R. L. (Orgs.) Leitura e escrita no contexto da diversidade. 6. ed. Porto Alegre: Mediação, 2015, p.7384.

GÓES, M.C.R.; BARBETI, R.S. As interações da criança surda no espaço do recreio e sua formação bilíngue. In: LODI, A.C.B.; LACERDA, C.B.F. (Orgs.) Uma escola, duas línguas: letramento em língua portuguesa e língua de sinais nas etapas iniciais de escolarização. 2. ed. Porto Alegre: Mediação, 2010, p. 127141.

GUARINELLO, A. C. O papel do outro na escrita de sujeitos surdos. São Paulo: Plexus, 2007.

LACERDA, C. B. F. Educação Inclusiva Bilíngue: Acompanhamento Implicações para Ações Pedagógicas junto a Alunos Surdos no Ensino Fundamental. Relatório Científico FAPESP, Processo 2012/17730-9. Universidade Federal de São Carlos, São Carlos, 2014.

LACERDA, C. B. F. Educação Inclusiva Bilíngue: Acompanhamento Implicações para Ações Pedagógicas junto a Alunos Surdos no Ensino Fundamental. Projeto em Parceria com a Secretaria Municipal de Educação de São Carlos-SP e Universidade Federal de São Carlos, financiado pela FAPESP Processo 2012/17730-9, modalidade Escola Pública. 2016.

LACERDA, C. B. F.; LODI, A. C. B. Ensino-aprendizagem do português como segunda língua: um desafio a ser enfrentado. Uma Escola, Duas Línguas: letramento em língua portuguesa e língua de sinais nas etapas iniciais de escolarização. 2. ed. Porto Alegre: Mediação, 2010, p. 143-159.

LODI, A. C. B. Ensino da língua portuguesa como segunda língua para surdos: impacto na Educação Básica. In: LACERDA, C. B. F., SANTOS, L. F. (Org.). Tenho um aluno surdo, e agora? Introdução à Libras e educação de surdos. 1. ed. São Carlos: EduFSCar, 2013, p. 50-65. 
MAYRINK-SABINSON, M. L. T. Um evento singular. In: ABAURRE, M. B. M.; FIAD, R. S.; MAYRINK-SABINSON, M. L. T. Cenas de aquisição da escrita - 0 sujeito e o trabalho como texto. Campinas, SP: Associação de leitura do Brasil (ABL): Mercado de Letras, 1997, p.37-49.

PEIXOTO, R. C. Algumas considerações sobre a interface entre a língua brasileira de sinais (LIBRAS) e a língua portuguesa na construção inicial da escrita pela criança surda. Cad. Cedes, Campinas, v. 26, n. 69, p. 205-229, maio/ago, 2006.

PEREIRA, M. C. C. Leitura, escrita e surdez. Secretaria de Educação, CENP/CAPE, 2 ed, São Paulo: FDE, 2009, p. 54-99.

PEREIRA, M. C. C. Papel da língua de sinais na aquisição da escrita por estudantes surdos. In: LODI, A. C. B. et al. (Orgs.). Letramento e minorias. 7. ed. Porto Alegre: Mediação, 2014a, p. 45-52.

PEREIRA, M. C. C. O ensino de português como segunda língua para surdos: princípios teóricos e metodológicos. Educar em Revista, Curitiba, Edição Especial, n. 2, p. 143-157, Editora UFPR, 2014b.

PINO, A. As marcas do humano: às origens da constituição cultural da criança na perspectiva de Lev S. Vigotski. São Paulo: Cortez, 2005.

REIS, V. S. A definição do diário como um gênero: entre diário íntimo e o diário de aprendizagem. Veredas Atemática, PPG Linguística/UFJF - Juiz de Fora, V.16, n. 2, p.120-132, 2012.

SANTOS, W. J. O aluno surdo em escola comum de ensino regular: inclusão bilíngue ou inserção monolíngue? Tear: Revista de Educação Ciência e Tecnologia, Canoas, v.2, n.1, p. 1-14, 2013.

SILVA, J. D.; STURM, I. N. Escrita e subjetividade: as marcas de autoria no texto escolar, 2013. Disponível em: http://hdl.handle.net/10183/96181. Acesso em: 20 abr. 2018. 
VIANA, M. M. C; LIMA, V. S. a escrita da língua portuguesa como segunda língua por surdos nas redes sociais. Revista de Letras, v.1, n.35, jan.-jun., p. 7$22,2016$.

VYGOTSKI, L. S. Obras Escogidas III. Problemas del desarrollo de la psique. Madrid: Machado Grupo de Distribución, 2012.

VYGOTSKI, L. S. Obras Escogidas I. El significado histórico de la crisis de la Psicología. Madrid: Machado Grupo de Distribución, 2013.

VYGOTSKI, L. S. Obras Escogidas II. Pensamiento y Lenguage. Conferencias sobre Psicología. Madrid: Machado Grupo de Distribución, 2014.

VYGOTSKI, L. S. El desarrollo de los processos psicológicos superiores. 1 ed. 3 impressão. Espanha: Austral, 2017. 